\title{
Análisis multitemporal de la deforestación usando la clasificación basada en objetos, distrito de Leymebamba (Perú)
}

\section{Multitemporal analysis of deforestation using object based classification, Leymebamba district (Peru)}

${ }^{a}$ Miguel Enrique Mendoza Chichipe ${ }^{1}$, Rolando Salas López ${ }^{1 *}$ y ${ }^{b}$ Elgar Barboza Castillo ${ }^{1}$

\section{RESUMEN}

El estudio consistió en determinar los cambios en la cobertura de bosques a causa de la deforestación entre los años 1987-2016, en Leymebamba, distrito que ha sido altamente alterado por la práctica de la agricultura migratoria. Para esto se utilizaron cuatro imágenes Landsat TM-OLI, de los años 1989, 1998, 2007 y 2016, sobre las cuales se realizaron los respectivos procesamientos. La obtención de cobertura y usos del suelo se realizó mediante la clasificación basada en objetos, de la cual se obtuvieron cinco representaciones de cobertura. En la validación temática se obtuvo una exactitud global de 85,2\% y un índice de kappa de 0,763, que indica una considerable precisión en la clasificación. Se encontró una alta deforestación en la temporada 1989-1998, con una tasa de 262,7 ha/año. Finalmente, para las temporadas 1998-2007 y 2007-2016, las tasas de deforestación descendieron a 34,8 ha/año y 58,2 ha/año, respectivamente.

Palabras clave: Deforestación, Leymebamba, índice kappa, OBIA.

\begin{abstract}
The study consisted in determining the changes in forest cover due to deforestation between 1987-2016, in Leymebamba, a district that has been highly altered by the practice of migratory agriculture. Four Landsat TM-OLI images were used for this purpose, 1989, 1998, 2007 and 2016, which were processed. In order to obtain land cover and land uses, it was performed using the object-based classification, from which five coverage representations were obtained. In the thematic validation an overall accuracy of $85.2 \%$ and a kappa index of 0.763 were obtained, which indicates a considerable precision in the classification. A high deforestation was found in the 1989-1998 season, with a rate of $262.7 \mathrm{ha} /$ year. Finally, for the following seasons, 1998-2007 and 2007-2016, deforestation rates dropped to $34.8 \mathrm{ha} /$ year and $58.2 \mathrm{ha} /$ year, respectively.
\end{abstract}

Keywords: Deforestation, Leymebamba, kappa index, OBIA.

\footnotetext{
Universidad Nacional Toribio Rodríguez de Mendoza de Amazonas (UNTRM-A), Instituto de Investigación para el Desarrollo Sustentable de Ceja de Selva, Calle Higos Urco No 342-350-356, Calle Universitaria N 304, Chachapoyas, Perú äE-mail:mchichiple@indes-ces.edu.pe ${ }^{\mathrm{b}} \mathrm{E}-\mathrm{mail}$ : ebarboza@untrm.edu.pe

"Autor de correspondencia: E-mail: rsalas@indes-ces.edu.pe
} 


\section{INTRODUCCIÓN}

La deforestación se ha convertido en una preocupación a nivel mundial por la pérdida de cobertura vegetal, ya que este gran ecosistema regula el clima y mitiga el efecto invernadero producidos por los gases contaminantes en la atmosfera, que tiene consecuencias económicas y sociales negativas (Moreno, 2013). En consecuencia surge la necesidad de conocer los factores que se relacionan con el cambio de cobertura y uso de suelo, a través de investigaciones que se enfocan en descubrir nuevos sistemas de monitoreo e indagar situaciones futuras (Osorio et al., 2015). .

El Perú mantiene el décimo puesto a nivel mundial de áreas con mayor densidad forestal. Más de la mitad del país, aproximadamente 260000 millas cuadradas $\left(673109 \mathrm{~km}^{2}\right)$, se encuentra cubierto por bosques. Solo Brasil cuenta con un área mayor de bosque tropical amazónico. La Amazonia es una de las principales regiones en peligro de deforestación, con expectativas de presentar mayor deforestación y degradación de los bosques a nivel mundial para el año 2030, siendo las principales causas de la deforestación la agricultura a menor escala, la minería comercial y la construcción de infraestructuras. La degradación de los bosques es causada principalmente por la tala ilegal. Cerca de 1100 millas cuadradas $\left(2849 \mathrm{~km}^{2}\right)$ de bosques peruanos son talados anualmente, y casi $80 \%$ de ellos de manera ilegal. (Marapi, 2013; Smith y Schwartz, 2015).

Los sistemas de información geográfica (SIG), la teledetección y el uso de imágenes satelitales, tienen diferentes aplicaciones en ámbitos ambientales, donde destaca la detección de cambios que ocurren a través del tiempo en la superficie terrestre, causados principalmente por actividades antrópicas y fenómenos naturales. La información obtenida por medio del análisis de imágenes satelitales sobre los procesos dinámicos de los cambios en la cobertura de suelo son importantes y necesarios, porque proporcionan la base para conocer las tendencias de los procesos de degradación, desertificación y pérdida de la biodiversidad de un territorio (Ramos et al., 2004). De acuerdo a
Meza y Díaz (2011), la labor primordial de un SIG radica en apoyar y asistir en la toma de decisiones espaciales para el manejo y conservación de recursos. Asimismo, su objetivo es el de convertir datos geográficos en información auténtica para la toma de decisiones ambientales, con el uso de herramientas y modelos analíticos derivados de distintas disciplinas.

La clasificación de imágenes satelitales es una herramienta indispensable en la planificación y gestión del territorio, donde la supervisada y no supervisada son las más conocidas y utilizadas, las cuales se basan en el análisis de los pixeles de las imágenes. El análisis de imágenes basado en objetos es un método que en los últimos tiempos se ha desarrollado de forma avanzada, en la mejora de los algoritmos y softwares; este tipo de clasificación se basa en la identificación de objetos, es decir grupo de pixeles continuos que tienen información y comportamientos similares, donde los resultados dependen de la resolución de las imágenes (Perea et al., 2009).

Esta investigación se planteó con los siguientes objetivos: analizar las imágenes satelitales mediante la Clasificación basada en Objetos conocida como OBIA (Object Based Imagen Analysis), en función de la cobertura y usos de suelo del distrito de Leymebamba; realizar un comparativo multitemporal de la dinámica de los bosques del distrito a través de la cuantificación de extensiones de las coberturas presentes en la zona de estudio; y estimar la tasa de deforestación en el distrito de Leymebamba entre los años 1989 y 2016. Todo esto con el fin de reflejar los cambios en la cobertura boscosa en el distrito de Leymebamba desde 1989 al 2016, lugar donde hubo gran incidencia por parte de las actividades humanas sobre la cobertura de bosques, lo que en términos conceptuales se llama deforestación, que implica la pérdida permanente de la cubierta de bosque e implica la transformación en otro uso de la tierra como para la agricultura, pasto, reservas de aguas y áreas urbanas (FAO, 2012). Asimismo se conoce que en las últimas décadas la actividad ganadera se desarrolla sobremanera dentro de la provincia de Chachapoyas (ZEE, 2010), esto conlleva a que se 
amplíen terrenos de pastizales, con la modificación y la pérdida de bosques correspondiente.

\section{MATERIAL Y MÉTODOS}

\section{Área de estudio}

La zona de estudio, se ubica en el distrito de Leymebamba, provincia de Chachapoyas, departamento de Amazonas (Figura 1).

\section{Obtención de imágenes Landsat}

Para la obtención de imágenes de satélite, primero se ubicó el área de estudio para luego extraer las imágenes de diferentes años o temporadas de la herramienta U.S. Geological Survey. Además se seleccionaron los sensores Landsat con nubosidad 30\%, de los cuales se obtuvieron resultados de imágenes en diferentes fechas. De acuerdo a esta adquisición se obtuvieron y se utilizaron cuatro imágenes, tres del sensor Landsat 5 TM y una de Landsat 8 OLI-TIRS, con diferencia de nueve años en cada imagen satelital.

\section{Pre-procesamiento de imágenes}

Esta etapa consistió en el tratamiento de imágenes satelitales. En primer lugar se realizó la corrección geométrica, que es la modificación de la geometría de la imagen respecto a la geometría de la superficie terrestre (Pérez y Muñoz, 2006; Gonzaga, 2014). Esta corrección se trabaja en base a puntos de control terrestre (GCPs); estos son extraídos del área de estudio y luego procesados en el software ERDAS IMAGINE. En segundo lugar, se procedió con la corrección atmosférica, necesaria debido a que las señales de radiación electromagnética percibidas por los sensores de los satélites en el espectro solar, son transformadas por absorción, dispersión y emisión, y generadas por gases y aerosoles que se hallan en la atmósfera; por ende la corrección atmosférica busca reducir o eliminar las distorsiones en las imágenes

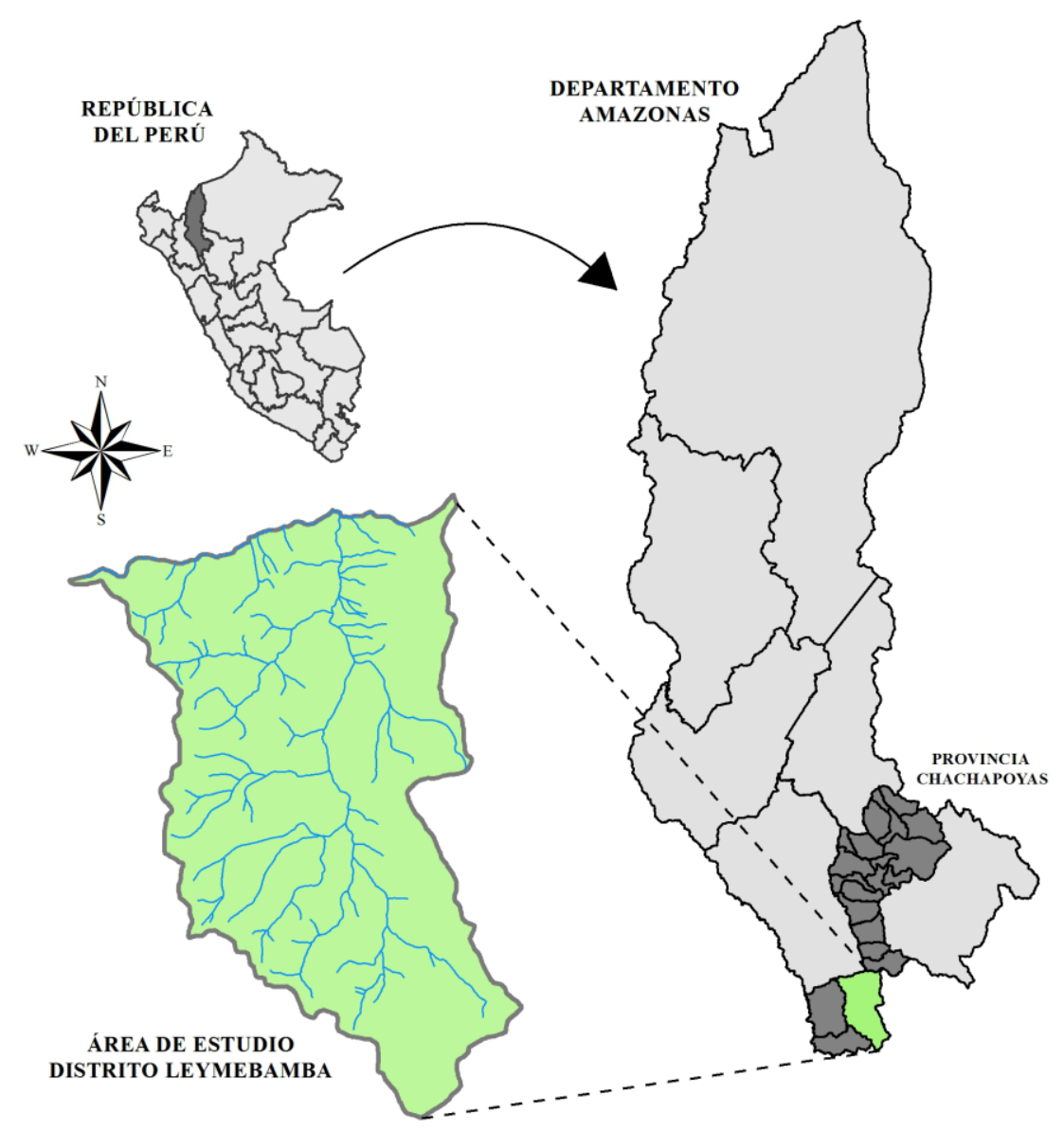

Figura 1. Ubicación de la zona de estudio en el distrito de Leymebamba (provincia de Chachapoyas) 
producto de la interacción entre el sensor y la atmósfera. Po otro lado la corrección busca recuperar la radiancia intrínseca del objeto de estudio, para esto se convierten los valores obtenidos (niveles digitales) por el sensor remoto en valores de reflectancia en superficie (APN, 2005, Gonzaga, 2014; Aguilar et al., 2015). La corrección atmosférica se realizó a partir de datos (radiancia, reflectancia) de la propia imagen, ya que es un método más operativo, pues no requeriría información externa y facilitaría una corrección completa de los datos. Esta se hizo utilizando el software de procesamiento ERDAS IMAGINE 2014 a través de su extensión ATCOR.

\section{Procesamiento de las imágenes}

\section{Clasificación basada en objetos (OBIA)}

A diferencia de la clasificación por pixel, más conocida como clasificación supervisada y no supervisada, la clasificación basada en objetos tiene mejores resultados, especialmente cuando se utilizan imágenes de alta resolución; esto consiste en encontrar un objeto (relación muchos a uno, píxeles a objeto y no por píxel como se realiza en la clasificación per pixel) utilizando las formas geométricas, la información espectral, espacial y el análisis de vecindad definidos para un objeto en particular (Rodríguez, 2011; Fulgencio, 2012); a continuación acceder a una mejor fidelidad en la clasificación de la cobertura de superficie terrestre.
En consecuencia, se adapta mejor a estudios ecológicos del paisaje (Peralta-Ribero et al., 2015). El procesamiento de imágenes como segmentación, se define como el proceso por el cual se extrae de una imagen información (características o atributos) considerable a partir de su división en diferentes regiones homogéneas (Ardila et al., 2004). La clasificación basada en objetos se compone de dos fases: la segmentación de la imagen (localizar el objeto), y la clasificación del objeto. La primera se fundamenta en la formación de objetos mediante la unión de píxeles, posteriormente la clasificación se realiza utilizando las características de los objetos. La segunda parte, consiste en definir el conjunto de reglas para el objeto a clasificar (similar a la clasificación supervisada), estableciendo variables de la clasificación como los atributos espectrales, los atributos geométricos y de vecindad, que contiene un objeto en específico, y están representados a través de la información de una imagen (Vidal et al., 2009; Rodríguez, 2011; Teo y Huang, 2016). El proceso de clasificación se desarrolló en el software ENVI mediante su herramienta Feature Extraction, con niveles de escala diferentes (Scale level 10 - merge lavel 80). Esta escala resultó mejor delineando o bordeando, ya que así se pueden diferenciar las coberturas y usos del suelo (Figura 2).

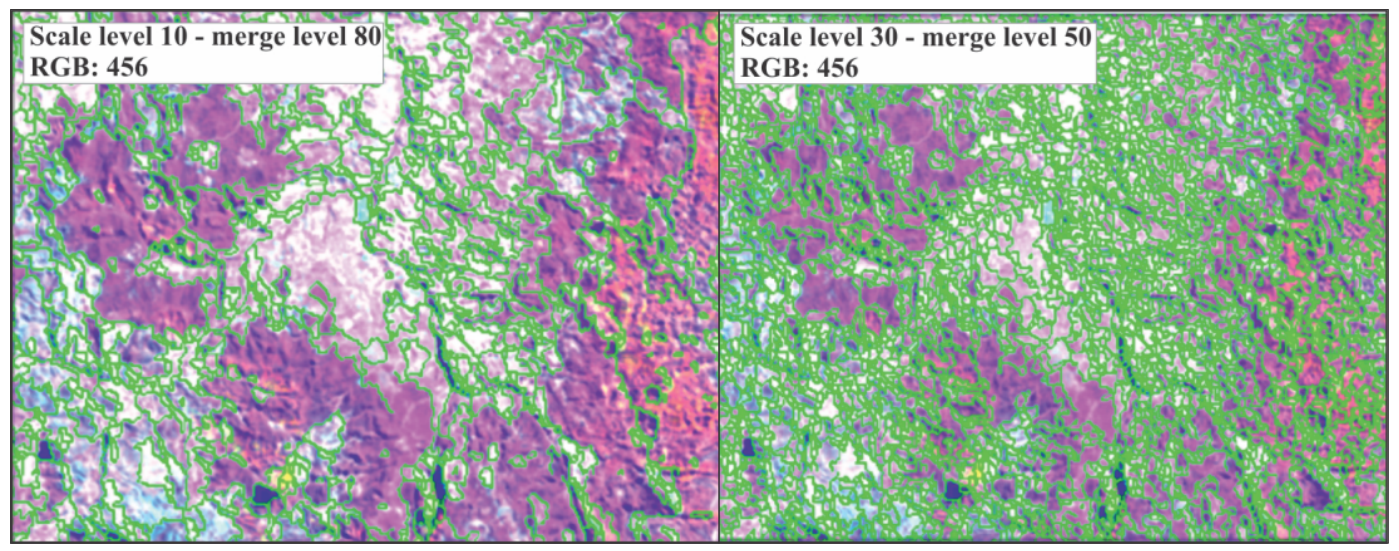

Figura 2. Diferencia en los niveles de segmentación y fusión (Scale level- Merge level) con imagen Lansat del año 1989. 


\section{Clases y usos de suelo en el distrito de Leymebamba.}

En base a la metodología de CORINE Land Cover adaptada para Perú, en la clasificación basada a objeto se consideraron cinco coberturas y usos de suelo en el distrito (tabla 1), las cuales son las más representativas del lugar además de ser factores de la dinámica de los bosques.

Tabla 1. Cobertura y usos del suelo en el distrito de Leymebamba

\begin{tabular}{|c|c|}
\hline Clases & Descripción \\
\hline Bosques & $\begin{array}{l}\text { Comprende las áreas naturales o seminaturales, constituidas principalmente por } \\
\text { elementos arbóreos de especies nativas o exóticas. Los árboles son plantas perennes } \\
\text { con solo tronco principal, que abarcan grandes áreas terrestres. }\end{array}$ \\
\hline Pastos y Cultivos & $\begin{array}{l}\text { Tierras cubiertas con hierba densa de composición florística, dedicadas al pastoreo } \\
\text { permanente y loscultivos. Abarca terrenos dedicados a la producción de materia prima } \\
\text { Los arbustos son plantas perennes, con estructura de tallo leñoso de altura entre } 0,5\end{array}$ \\
\hline Arbustales y herbazales & $\begin{array}{l}\text { m y } 5 \mathrm{~m} \text {, fuertemente ramificado en la base y sin una copa definida. Los herbazales } \\
\text { son aquellos ecosistemas donde predomina la vegetación herbácea. }\end{array}$ \\
\hline Cuerpos de agua & $\begin{array}{l}\text { Son los cuerpos y cauces de aguas permanentes, intermitentes y estacionales, } \\
\text { localizados en el interior del continente, como un lago, mar u océano que cubre parte } \\
\text { de la tierra. }\end{array}$ \\
\hline Zona urbana & $\begin{array}{l}\text { Son territorios cubiertos por estructura urbana, áreas verdes yredes d e comunicación } \\
\text { asociados a ella }\end{array}$ \\
\hline
\end{tabular}

\section{Post-procesamiento}

\section{Mejoramiento de objetos creados por la clasificación}

Proceso en el cual se mejora la información obtenida de la clasificación basada en objetos. Consistió en suavizar los polígonos que estaban en forma de pixeles, y delimitar sobre las imágenes de elementos u objetos (cobertura y usos del suelo) que no han sido obtenidos claramente en la clasificación. Este proceso se realizó en el software ArcGIS 10.3.

\section{Cálculo de la deforestación en el distrito de Leymebamba}

Posterior a la clasificación basada en objetos se realizó un análisis multitemporal con el fin de observar y calcular los cambios en la cobertura y usos del suelo; esto se realizó a través de la cuantificación de las áreas de cada cobertura, lo que determinó las tasas de deforestación en las temporadas 1989-1998, 1998-2007, y 2007-2016.

\section{Evaluación de validación o exactitud temática}

La matriz de confusión o contingencia permite comparar dos clasificaciones, una definida por el usuario como base, y la otra la que se desea evaluar. Se construye una comparación matricial de clases realizadas de la propia clasificación, ubicada generalmente en diferentes sectores o en la totalidad del mapa, confrontando las clases de cada clasificación (Rodríguez, 2011). La validación de los resultados se efectuó mediante una matriz de confusión, elaboradas a partir de la tabulación cruzada de la información generada por la clasificación inicial y la verdad-terreno (muestreo). El número de puntos de muestra $(N)$ se obtiene mediante la siguiente fórmula binomial acierto y error (Chuvieco, 1995; Laurente, 2011).

$$
N=\frac{z^{2} \times p \times q}{E^{2}}=\frac{1.96^{2} \times 85 \times 15}{5^{2}}=195,92
$$

donde:

$\mathrm{Z}=$ curva normal para un nivel determinado de probabilidad $p=$ porcentaje de aciertos estimado $(85 \%)$

$\mathrm{q}=$ porcentaje de errores $(\mathrm{q}=1-\mathrm{p})$

$\mathrm{E}=$ nivel permitido de error

La exactitud global se obtuvo dividiendo la cantidad de puntos ubicados correctamente entre el total de puntos muestreados. El Índice Kappa $(\boldsymbol{k})$ se obtuvo con la siguiente fórmula (Chuvieco, 1995, Laurente, 2011):

$$
\mathbf{k}=\frac{\mathbf{N} \sum_{i=1}^{r} x_{i i}-\sum_{i=i}^{r} x_{i+} x_{+i}}{N^{2}-\sum_{i=i}^{r} x_{i+} x_{+i}}
$$

Dónde:

$\mathrm{r}=$ número de filas en la matriz

$\mathrm{X}_{\mathrm{ii}}=$ número de observaciones en la fila $\boldsymbol{i}$ y columna $\boldsymbol{i}$ 
$\left(\mathrm{X}_{\mathrm{i}+}, \mathrm{X}_{+\mathrm{i}}\right)$ son el total de marginal de fila $\boldsymbol{i}$ y columna $\boldsymbol{i}$, respectivamente

$\boldsymbol{N}$ es el total de observaciones

Las categorías de concordancia de la validación para el coeficiente kappa, están entre los rangos de 0 a 1, de la cual, para la validación temática, 0 se considera nula, 0,01-0,02 leve, 0,21-0,40 aceptable, 0,41-0,60 moderado, 0,61-0,80 considerable, y 0,81-1,00 casi perfecta (Rodríguez, 2011).

\section{RESULTADOS}

Cambios en la cobertura forestal en la temporada 1989-1998

Tomando como base al año 1989, los bosques poseían una vegetación densa con ausencia de perturbaciones, con una extensión de 15059,07 hectáreas (ha), que corresponde al 33,28\% del área de estudio. Para el año 1998, los bosques presentaron una extensión de 12694,49 ha, el 28,05\% del área de estudio y se reveló la pérdida de 2364,58 ha, siendo el 5,23\% de la extensión inicial, con una tasa de 262,7 ha/año. Pastos y cultivos reportaron un crecimiento considerable de sus extensiones de 1801,26 ha. Otro dato importante fue el crecimiento de la zona urbana, que pasó de 9,86 a 27,45 ha para el año 1998 (Tabla 2).

Cambios en la cobertura forestal en la temporada 1998-2007

En el año 2007, la clase de bosques tenía una extensión de 12381,01 ha, con una pérdida de 313,48 ha (el 0,69\%) de reducción correspondiente al área de bosques que hubo en 1998, obteniendo de esta temporada una deforestación de 34,8 ha/año. Pastos y cultivos, en comparación con la primera temporada disminuyeron su velocidad de crecimiento en sus extensiones en 384,87 ha. El área urbana continuó con un aumento de 23,41 ha, que para el año 2007 presentó 50,86 ha (Tabla 2).

Cambios en la cobertura forestal en la temporada 2007-2016

En el año 2016, los bosques presentaron una extensión de 11856,81 ha, con la pérdida 524,2 ha, siendo $1,16 \%$ de disminución correspondiente al área de bosques que hubo en el 2007, y se obtuvo una tasa deforestación de 58,2 ha/año. En este periodo se reveló que la cobertura de arbustales y herbazales disminuyó su área en 1201,5 ha para el año 2016. Esto afectó a la cobertura hacia pastos y cultivos, donde esta última presentó un aumento de 1714,8 ha, similar al de la primera temporada. Cabe resaltar, que de acuerdo a los resultados que se observan en la figura 3, la ampliación de pastos y cultivos es la que modifica la cobertura de bosques durante los tres periodos; este cambio tiene mayor incidencia en los alrededores de la zona urbana. La extensión de bosques perdidos entre 1989 y 2016 fue de 3202,26 ha, con una tasa de 118,6 ha/año (Tabla 2).

\section{Validación temática}

La validación de la clasificación del mapa generado del último año resultó en un índice de kappa de 0,763. Este indica una precisión considerable de acuerdo a la similitud de la clasificación de la imagen satelital con el terreno real y una exactitud global de $85,2 \%$ (Tabla 3 ).

Tabla 2. Áreas respectivas de los cinco tipos y usos del suelo resultado de la clasificación basada en objetos, de las cuales refleja la dinámica de la cobertura terrestre en el distrito de Leymebamba en tres temporadas diferentes (1989-1998; 1998-2007 y 2007-2016)

\begin{tabular}{|c|c|c|c|c|c|c|c|c|c|c|c|}
\hline \multirow{3}{*}{$\begin{array}{l}\text { Cobertura y usos } \\
\text { del suelo }\end{array}$} & \multicolumn{8}{|c|}{ Extensiones (has) } & \multicolumn{3}{|c|}{$\begin{array}{l}\text { Pérdida (-) y Ganancia (+) de } \\
\text { cobertura y usos del suelo (has) }\end{array}$} \\
\hline & \multicolumn{2}{|c|}{1989} & \multicolumn{2}{|c|}{1998} & \multicolumn{2}{|c|}{2007} & \multicolumn{2}{|c|}{2016} & \multicolumn{3}{|c|}{ Temporadas } \\
\hline & (ha) & $\%$ & (ha) & $\%$ & (ha) & $\%$ & (ha) & $\%$ & $\begin{array}{l}1989- \\
1998\end{array}$ & $\begin{array}{l}\text { 1998- } \\
2007\end{array}$ & $\begin{array}{l}2007- \\
2016\end{array}$ \\
\hline Bosques & 15059,07 & 33,28 & 12694,49 & 28,05 & 12381,01 & 27,36 & 11856,81 & 26,20 & $-2364,58$ & $-313,48$ & $-524,20$ \\
\hline Cultivos y pastos & 6559,25 & 14,49 & 8360,51 & 18,48 & 8745,38 & 19,33 & 10460,18 & 23,11 & 1801,26 & 384,87 & 1714,80 \\
\hline $\begin{array}{c}\text { Arbustales y } \\
\text { herbazales }\end{array}$ & 23598,44 & 52,15 & 24142,49 & 53,35 & 24047,95 & 53,14 & 22846,45 & 50,49 & 544,05 & $-94,54$ & $-1201,50$ \\
\hline Cuerpos de agua & 26,29 & 0,06 & & 0,06 & & 0,06 & 28,26 & 0,06 & 1,68 & $-0,26$ & 0,55 \\
\hline Zona Urbana & 9,86 & 0,02 & 27,45 & 0,06 & 50,86 & 0,11 & 61,21 & 0,14 & 17,59 & 23,41 & 10,35 \\
\hline \multicolumn{9}{|c|}{ Tasa de deforestación (ha/año) } & 262,73 & 34,83 & 58,24 \\
\hline \multicolumn{9}{|c|}{ Tasa de deforestación 1989-2016 (ha/año) } & & 118,6 & \\
\hline
\end{tabular}


Tabla 3. Matriz de confusión para la validación temática

\begin{tabular}{ccccccccc}
\hline Coberturas & Bosques & $\begin{array}{c}\text { Pastos y } \\
\text { cultivos }\end{array}$ & $\begin{array}{c}\text { Arbustales } \\
\text { y herbazales }\end{array}$ & $\begin{array}{c}\text { Cuerpos } \\
\text { de agua }\end{array}$ & $\begin{array}{c}\text { Zona } \\
\text { urbana }\end{array}$ & Total & $\begin{array}{c}\text { Exactitud } \\
\text { mapa }\end{array}$ & $\begin{array}{c}\text { Error } \\
\text { comisión }\end{array}$ \\
\hline $\begin{array}{c}\text { Bosques } \\
\text { Pastos y cultivos }\end{array}$ & 41 & 1 & 6 & & & 48 & 85,42 & 14,58 \\
$\begin{array}{c}\text { Arbustales y } \\
\text { herbazales }\end{array}$ & 7 & 35 & 2 & & & 39 & 89,74 & 10,26 \\
$\begin{array}{c}\text { Cuerpos de agua } \\
\text { Zona urbana }\end{array}$ & 10 & 88 & & & 105 & 83,81 & 16,19 \\
\hline Total & 50 & 46 & 97 & 1 & 2 & 196 & & \\
\hline $\begin{array}{c}\text { Exactitud de } \\
\text { campo (\%) }\end{array}$ & 82,00 & 76,09 & 90,72 & 100,00 & 100,00 & & 167 & \\
\hline Error de Omisión & 18,00 & 23,91 & 9,28 & 0,00 & 0,00 & \multicolumn{2}{c}{ Índice Kappa $=0,763$} \\
\hline
\end{tabular}

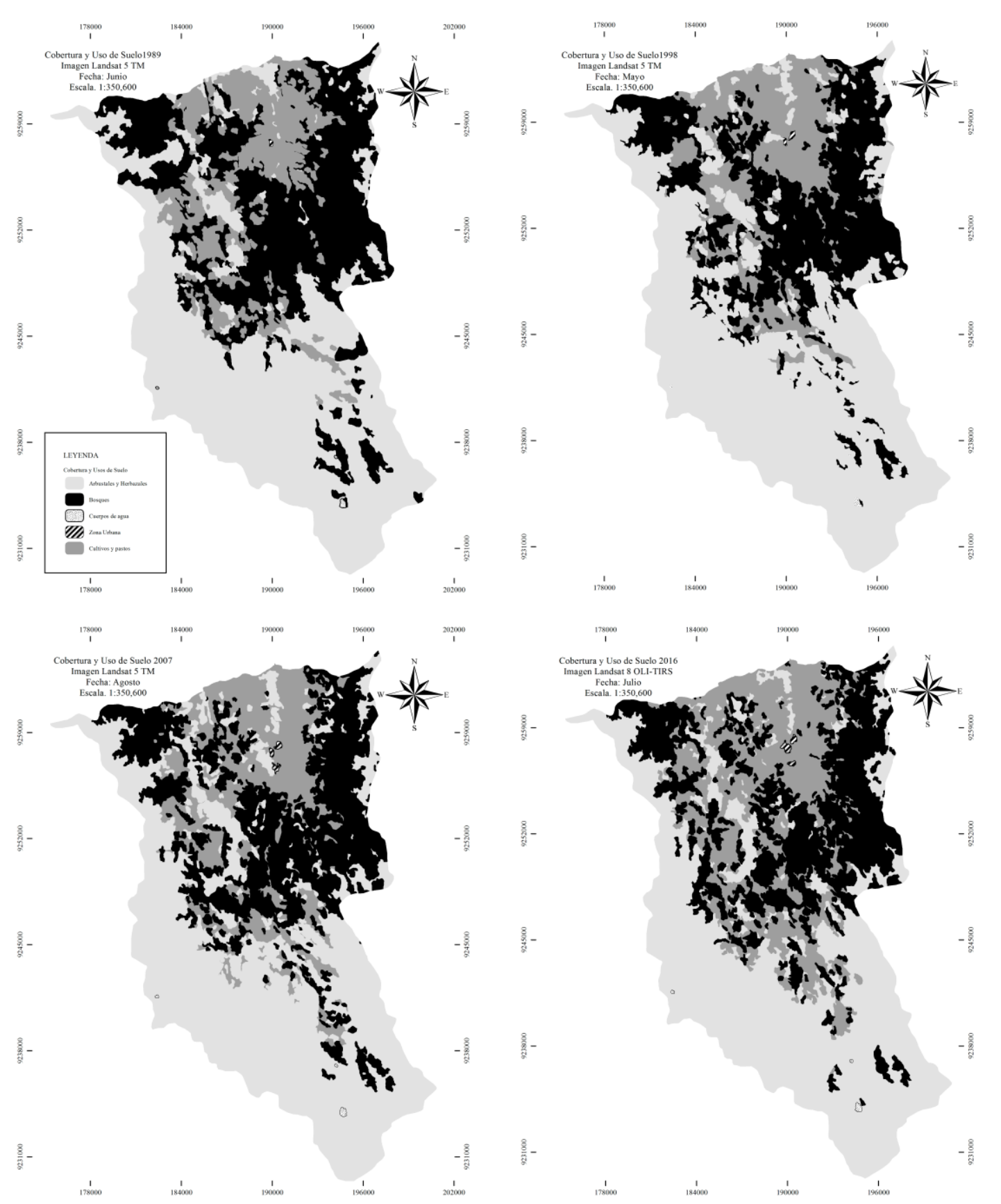

Figura 3. Mapas de cobertura y usos de suelo del distrito de Leymebamba para los años 1989, 1998, 2007 y 2016. 


\section{IV.DISCUSIÓN}

\section{Cambio en la cobertura de bosques en la tempora- da 1989-1998}

En esta temporada se reporta una considerable pérdida de bosques, de 2364,58 ha, con una tasa anual de deforestación de 262,7 ha/año. Esto se sustenta principalmente por el expansión de la actividad agrícola y las migraciones poblacionales que ocurrieron en dicha temporada. De acuerdo a los resultados, la primera se demuestra debido al aumento notable de 1801,26 ha de las extensiones de pastos y cultivos. Asimismo, la segunda se debe a las migraciones de la sierra que ocurrieron en esta temporada (1989-1998), especialmente de los cajamarquinos (Departamento de Cajamarca), que se movilizaron hacia nuevos territorios con el propósito de aprovechar la riqueza de los recursos naturales y para el dominio de terrenos de las regiones norte del país (Salas et al., 2014; Sánchez, 2015).

Según el INEI (1995), en el censo del año 1981 y 1993, reportó una migración de 81000 a 108000 personas, respectivamente, considerando con estas cifras a Cajamarca y San Martín como los departamentos expulsores de población de aquella época. Parte de aquella migración llegó a diferentes distritos del departamento de Amazonas en busca de tierra para la expansión de la frontera agrícola.

Baluarte (1994), en su diagnóstico del sector forestal en el país, reportó que la deforestación para el año 1990, el departamento de Amazonas ocupaba el primer lugar, con un 45,21\% de extensión de bosques amazónicos perdidos (3695482 ha), seguido de San Martín y Loreto. Asimismo, en el estudio de la deforestación de la amazonia peruana hasta el 2000 a nivel departamental, San Martín presentó la mayor superficie deforestada con 1327736,15 ha $(18,51 \%)$, seguido de Amazonas con 1001540,11 ha (13,96\%) y Loreto con 945642,15 ha $(13,18 \%)$ (MINAM, 2009; BID, 2012).

\section{Temporadas 1998-2007 y 2007-2016}

La deforestación en estas dos temporadas, 1998-2007 y 2007-2016, provocó en el área de estudio una considerable disminución de la misma, entre 34,8 ha/año y $58,2 \mathrm{ha} /$ año, respectivamente. Esto se debe, a que la actividad ganadera ya empezaba a desarrollarse y las migraciones poblacionales tanto hacia la región y al distrito empezaban a descender en dichas temporadas. Con respecto a la dinámica poblacional, Sánchez (2015), reportó que en el último censo de población del 2007, que las cifras muestran una disminución de las migraciones, comparado con lo que pasó en el quinquenio previo al censo del año 1993 (1993-1988). En este censo se reportó la disminución tanto en términos absolutos como relativos. Hay que añadir que la migración interdepartamental disminuyó, y pasó de representar el 8,4\% de la población en el año 1993, al $6,2 \%$ del total de la población en el año 2007. Por lo tanto, la disminución de la deforestación como se ha mencionado, se debe en gran parte al descenso de cifras de migración poblacional dentro del país en aquellas épocas, por lo que el apoderamiento de nuevos territorios y el aprovechamiento de sus recursos naturales de cierto modo tendieron a disminuir.

Otros estudios, como el realizado por el BID (2012), reportó que los departamentos de San Martín, Amazonas y Junín, fueron los que ocuparon los primeros puestos en tasas de deforestación hasta el año 2000, pero que para los años 2000 al 2009 presentaron una tendencia clara hacia un descenso de su deforestación hasta el 2005 y mantienen bajas tasas comparativas en el último, del 2005 al 2009. Salas et al. (2014), en su estudio de deforestación en el distrito de Florida reportaron una tasa de pérdida de bosques de 232,2 ha/año durante la temporada 1987-2000. Por el contrario, en la temporada 2000-2013, se notó un descenso considerable de la deforestación, de aproximadamente 19,52 ha/año. Asimismo, el MINAM (2014), reportó que Amazonas mantiene una tasa baja de deforestación, de 4261,55 ha/año, colocándose en el séptimo lugar, donde el departamento que lidera hoy en día es San Martín, con 35278,85 ha/año.

\section{CONCLUSIONES}

A partir del análisis de imágenes basado en objetos a través de la segmentación (agrupación de pixeles) se puede extraer información (espectral y espacialmente) de la cobertura terrestre, con alto nivel de precisión y rapidez de ejecución, debido a que este método se va mejorando y adaptando a las condiciones existentes en la actualidad. Este análisis está mucho más cerca de la percepción/visión humana. . Los resultados de la clasificación de acuerdo a la validación temática muestran una considerable exactitud. Asimismo, se recomienda tener resultados de varias segmentaciones de las imágenes antes de realizar la clasificación de las mismas, ya que esto asegura tener los niveles de escala adecuados para la clasificación. Asimismo, al utilizar imágenes de alta resolución aseguraría mejores resultados, por lo que otros estudios no tuvieron mayor exactitud al utilizar imágenes con resoluciones inferiores. 
La comparación multitemporal de las imágenes con respecto al área de estudio (distrito de Leymebamba), reflejan un gran cambio en la cobertura de los bosques causado por la ampliación de fronteras agrícolas. Entre los tres periodos (1989-1998, 1998-2007 y 2007-2016), el primero presenta una alta tasa de deforestación (262,7 ha/año) en comparación con las dos temporadas restantes, con un ligero aumento en la tercera temporada, 34,8 ha/año y 58,2 ha/año, respectivamente. De manera general la extensión de bosques perdidos entre 1989 y 2016 resultó de 3202,26 ha, con una tasa de 118,60 ha/año.

\section{REFERENCIAS BIBLIOGRÁFICAS}

Aguilar, H., R. Mora y C. Vargas. "Metodología para la corrección atmosférica de imágenes Aster, Rapideye, Spot 2 y Landsat 8 con el Módulo Flaash del Software ENVI". Revista Geográfica de América Central, 7(2015):39-59.

APN (Administración de Parques Nacionales). "Protocolo para el pre procesamiento de imágenes satelitales Landsat para aplicaciones de la administración de parques nacionales". Buenos Aires (Argentina), 2005.

Ardila J., O. Espejo y J. Herrera. "Validación de una metodología de clasificación de imágenes satelitales en un entorno orientado a objetos". Ingeniería, 10(2004): 61-69.

Baluarte, J. "Diagnóstico del sector forestal en la Región Amazónica, Instituto de Investigación de la Amazonia Peruana (IIAP). Iquitos (Perú), 1994.

BID (Banco Interamericano de Desarrollo). Elementos para la identificación de áreas con mayor potencial para reducir emisiones de GEI en el sector forestal". Fondo Estratégico sobre el Clima Programa de Inversión Forestal. Lima (Perú), 2012.

Chuvieco, E. "Fundamentos de teledetección ambiental”. Barcelona (España), 1995.

FAO (Organización de las Naciones Unidas para la Alimentación y la Agricultura). "Evaluación de los recursos forestales: Términos y definiciones". Roma, (Italia), 2012.

Fulgencio C. "Análisis de imágenes basado en objetos
(OBIA) y aprendizaje automático para la obtención de mapas de coberturas del suelo a partir de imágenes de muy alta resolución espacial. Aplicación en la Unidad de Demanda Agraria $\mathrm{N}^{\circ}$ 28, Cabecera del Argos. Tesis doctoral. Universidad de Murcia. Asociación Española de Teledetección".Revista de Teledetección, 38(2012): 89-90.

Gonzaga, C. "Aplicación de índices de vegetación derivados de imágenes satelitales Landsat 7 ETM + y Aster para la caracterización de la cobertura vegetal en la zona centro de la provincia de Loja, Ecuador", Tesis de Maestría para optar el grado académico de Magister en Geomática. Loja(Ecuador), 2014.

INEI (Instituto Nacional de Estadística e Informática). "Migraciones Internas en el Perú". Lima (Perú), 1995

Laurente, M. "Medición de la deforestación mediante percepción remota en la microcuenca río Supte, Tingo María - Perú”. GeoFocus (Informes), 11(2011): 1-15.

Marapi, R. "La deforestación de los bosques". Revista agraria, 1(2013): 6-13.

Meza, C. y A. Díaz. "Evaluación de la deforestación y sus impactos ambientales: provincia de Padre Abad". Investigaciones sociales, 27(2011): 121-131.

MINAM (Ministerio del Ambiente). "Mapa de deforestación de la Amazonia Peruana 2000, Programa de Fortalecimiento de Capacidades Nacionales para manejar el impacto del Cambio Climático y la Contaminación del Aire". Lima (Perú), 2009.

MINAM (Ministerio del Ambiente). "Memoria técnica: cuantificación de la cobertura de bosque y cambio de bosque a no bosque de la Amazonía peruana. Período 2009-2010-2011. Lima (Perú), 2014.

Moreno R. "Cálculo de la tasa de deforestación anual en el periodo 2001-2011 en la provincia de Tambopata con imágenes de NDVI (MOD13) 
de MODIS, mediante relación de ajuste de recta”. Tambopata (Perú), 2013.

Osorio, L.P., J.F. Mas, F. Guerra y M. Maass. “Análisis y modelación de los procesos de deforestación: un caso de estudio en la cuenca del río Coyuquilla, Guerrero, México". Investigaciones Geográficas, Boletín, 88(2015): 60-74.

Peralta-Ribero, C., J. Torrico, V.A. Vos, M. Galindo y C. Contreras-Servín. "Tasas de cambios de coberturas de suelo y deforestación (19862011) en el municipio de Riberalta, Amazonía boliviana”. Ecología en Bolivia, 50(2015): 91-114.

Perea A.J., J.E. Meroño y M.J. Aguilera. "Clasificación orientada a objetos en fotografías aéreas digitales para la discriminación de usos del suelo". INCI, 34 (2011): 17-30.

Pérez, C. y A. Muñoz. "Teledetección Nociones y Aplicaciones”. Universidad de Salamanca. Salamanca (España), 2006.

Ramos, R., D. Palma, C. Ortiz, C. Ortiz y G. Díaz. "Cambios de uso de suelo mediante técnicas de sistemas de información geográfica en una región cacaotera". Terra Latinoamericana, 12(2004): 267-278.

Rodríguez, A. "Metodología para detectar cambios en el uso de la tierra utilizando los principios de la clasificación orientada a objetos, estudio de caso piedemonte de Villavicencio, Meta". Tesis presentada como requisito parcial para optar al título de Magister en Geomática, Universidad Nacional de Colombia. Bogotá (Colombia), 2011.

Salas R., E. Barboza y M. Oliva. "Dinámica multitemporal de índices de deforestación en el distrito de Florida, departamento de Amazonas, Perú". Rev. INDES, 1(2014): 18-27.

Sánchez, A. "Migraciones Internas del Perú, Organización Internacional para las Migraciones (OIM)”. Lima(Perú), 2015.

Smith, J. y J. Schwartz. "La deforestación en el Perú, Fondo Mundial para la Naturaleza WWF
Perú”. Lima(Perú), 2015.

Teo, T.A. y C.H. Huang. "Object-Based land cover classification using airborne Lidar and different spectral images. Terr. Atmos. Ocean. Sci., 27(2016): 491-504.

Vidal. A, M.R. Moreno y M. Llopis. “Clasificación por objetos en imagen aérea de alta resolución para detección de cambios en zona urbana. Teledetección: Agua y Desarrollo Sostenible”. XIII Congreso de la Asociación Española de Teledetección, 549-552. Sevilla (España), 2009.

ZEE (Zonificación Ecológica y Económica del departamento de Amazonas). Instituto de Investigaciones de la Amazonia Peruana (IIAP). Iquitos (Perú), 2010. 